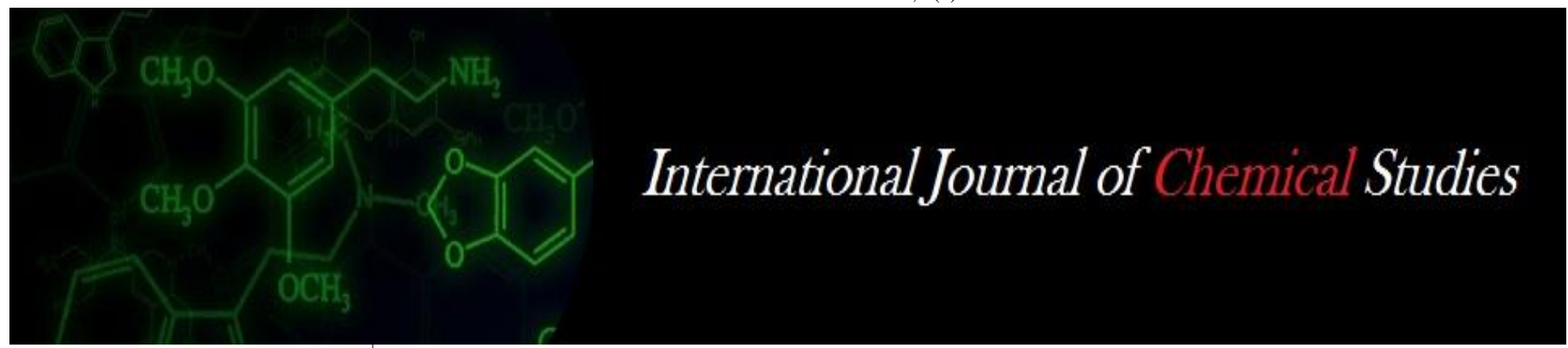

P-ISSN: 2349-8528

E-ISSN: 2321-4902

www.chemijournal.com

IJCS 2020; 8(6): 2433-2438

(C) 2020 IJCS

Received: 12-09-2020

Accepted: 16-10-2020

\section{CS Maurikaa}

Indian Institute of Food

Processing Technology,

Thanjavur, Tamil Nadu, India

\section{B Jaganivash}

Indian Institute of Food

Processing Technology,

Thanjavur, Tamil Nadu, India

S Shanmugasundaram

Indian Institute of Food

Processing Technology,

Thanjavur, Tamil Nadu, India

Corresponding Author:

S Shanmugasundaram

Indian Institute of Food

Processing Technology,

Thanjavur, Tamil Nadu, India

\section{Comparative studies on physicochemical properties of virgin coconut oil (VCO) with different coconut oils}

\author{
CS Maurikaa, B Jaganivash and S Shanmugasundaram
}

DOI: https://doi.org/10.22271/chemi.2020.v8.i6ai.11135

\begin{abstract}
This study aims to compare the physicochemical properties of Virgin Coconut Oil (VCO), Refined, Bleached and Deodorized (RBD) oil and Cold Pressed Oil (CPO, Chekku oil). The physicochemical properties taken for the study includes moisture content, refractive index, saponification value, iodine value, acid value, unsaponifiable matter, polenske value and \% free fatty acids. The physicochemical properties of all three samples obtained are in compliance with Asian and Pacific Coconut Community (APCC) standards. Of all the samples, VCO showed 1.3\% FFA which was higher when compared, that it should be consumed only to a certain limit for cooking. VCO has very low moisture content of $0.11 \%$ where the shelf life of oil can be naturally preserved. The acid value of VCO was $2.7 \mathrm{mg} \mathrm{KOH} / \mathrm{g}$ which has the highest amount of AV whereas for other samples it was less than $1.0 \mathrm{mg} \mathrm{KOH} / \mathrm{g}$. These findings can be used for chemical analysis and adulteration detection.
\end{abstract}

Keywords: Virgin coconut oil (VCO), commercial coconut oil samples, physicochemical properties, APCC standard, free fatty acids (FFA)

\section{Introduction}

Coconut oil is an edible oil that has been consumed in tropical countries for thousands of years (Gopala et al., 2010) ${ }^{[14]}$. Over the last decade, the world production of coconut oil has been raised because of its edible characteristics. In the point of edible nature, there are two type of coconut oil, RBD (refined, bleached, and deodorized) which was used in major and the virgin coconut oil (VCO) where the consumption is comparatively low because of its high cost (Perera et al., 2020) ${ }^{[20]}$. It is largely consumed for both edible and non-edible purposes that includes cooking, bakery, confectionary, pharmaceutical, infant foods, and cosmetics (Dia et al., 2005; Gopala et al., 2010) ${ }^{[11,14] .}$

Commercial edible RBD coconut oil is derived from the kernel of Cocos nucifera L., a tropical plant (Gopala et al., 2010) ${ }^{[14]}$ from which dried copra was taken then extracted and the resulting crude oil is processed on an industrial scale by washing, bleaching and deodorization (F.M. Dayrit et al., 2007) ${ }^{[8]}$. Coconut oil contains 92\% saturated fatty acids (SFA) (Da Silva Lima \& Block, 2019) ${ }^{[7]}$ hence it is consumed less (Gopala et al., 2010) ${ }^{[14]}$. However, research on populations that eat diets high in coconut oil have shown no harmful effects on the population's health (Thampan et al., 2009). The major fatty acid of coconut oil is a mediumchain fatty acid (MCFA). MCFA serves as the source of energy and is easy to absorb, metabolize and store in the body (Schönfeld \& Wojtczak, 2016) ${ }^{[24]}$. Lipid oxidation is a significant degradation mechanism that occurs in oils, thereby affecting the organoleptic properties of food products coupled with oil (Perera et al., 2020) ${ }^{[20]}$. As coconut oil is composed of more saturated fatty acids, it is more resistant to oxidation and polymerization than the oils with unsaturated fatty acids (Da Silva Lima \& Block, 2019) ${ }^{[7]}$. But when the oil is processed, there are certain thermal and chemical treatments that influence the natural quality and composition of fatty acids (Vidya \& Seeja, 2016) ${ }^{[27]}$.

Virgin coconut oil (VCO) on the other hand, obtained from fresh and mature coconut kernels (12 months after pollination) (Cocos nucifera L.) by mechanical or natural means, with or without heat application, which does not alter the quality of the oil. VCO has not been exposed to chemical refining, deodorization and bleaching. In its natural state, it can be consumed without the need for further processing. Virgin coconut oil consists primarily of peroxidationresistant medium chain triglycerides. 
Colorless, sediment-free virgin coconut oil with a perfect, fresh coconut fragrance. It is free from rancid odor or taste (APCC, 2009; Nevin \& Rajamohan, 2004) ${ }^{[3, ~ 18] . ~ T h e ~}$ production can be of two methods which includes wet and dry methods (Ghani et al., 2018) ${ }^{[13]}$. In the dry method, the kernel is dried to remove the moisture from microbial invasion occurring. The dried kernel is pressed mechanically by means of bulls or electric source known as cold pressed oil. In contrast, in the wet method the VCO is extracted from the coconut meat/kernel by either chilling and centrifugation, enzymatic or fermentation to destabilize the emulsion of coconut milk without requiring the process of drying (Raghavendra \& Raghavarao, 2010) ${ }^{[22]}$. The lauric acid content, a medium chain fatty acid was present in high amount in the VCO that shows potential for anti-obesity treatments (Assunção et al., 2009; F.M. Dayrit, 2015) ${ }^{[5,9]}$. Due to the presence of higher MCFA they perform some specific functional properties (Savva \& Kafatos, 2015; Srivastava et al., 2018) [23, 25] that includes antiviral, antibacterial, antiplaque, antiprotozoal, healing, antiinflammatory and anti-obesity effects (German \& Dillard, 2004) ${ }^{[12]}$. And VCO also has several benefits for curing some minor illnesses (List, 2016) ${ }^{[16]}$ such as diarrhea, skin inflammations, gastrointestinal problems, minor wounds, injures and swelling (Nevin \& Rajamohan, 2006) ${ }^{[19]}$.

The VCO therefore exhibits more benefits in terms of both functional and nutritional aspects than other commercial edible coconut oil. Recently, here grows the interest in the consumption of VCO for cooking and medicinal benefits (Ghani et al., 2018) ${ }^{[13]}$. Due to its complicated processing steps, virgin coconut oil costs much more than other commercial coconut oils. Hence there is a risk of adulteration in VCO, so it was important to study the quality characteristics of VCO. Therefore, the subject of this paper is to focus on the comparative study of physicochemical properties of commercial edible RBD coconut oil, virgin coconut oil and cold pressed coconut oil.

\section{Material and Methods \\ 2.1 Raw material}

The coconut oils samples that include virgin coconut oil (VCO) were purchased from Pavithra Kera product, Palakkad (Kerala), Refined, Bleached and Deodorized coconut oil (RBD) and cold pressed coconut oil (CPO) were purchased from the local market in the city. All solvents and chemicals used were of analytical grade.

\subsection{Determination of physicochemical properties}

The physicochemical properties were carried out for all the three coconut oil samples. All the tests were performed with reference to the Food Safety and Standards Authority of India (FSSAI), American Oil Chemists Society (AOCS), Asian Pacific Coconut Community (APCC) and Indian standards (IS).

\subsubsection{Moisture content (MC)}

Moisture and volatile are an important factor to determine the oil quality. Moisture content (MC) for the different oils samples were determined based on the American Oil Chemists Society (AOCS) (Firestone et al., 2009) method. About $5.0 \mathrm{~g}$ of oil sample was weighed in a crucible with lid which was preheated, weighed and dried. It was then heated at $105{ }^{\circ} \mathrm{C}$ for about 24 hours until there is no change in the successive observations. The crucible with sample was then placed in the desiccator and allowed to cool to a room temperature. The crucible with oil sample was then reweighed. The moisture content were then calculated using the following formula:

$$
\text { Moisture content }(\%)=\frac{\text { initial weight-final weight }}{\text { initial weight }} \times 100 \%
$$

\subsubsection{Refractive index at $40{ }^{\circ} \mathrm{C}(\mathrm{RI})$}

The refractive index (RI) of the oil samples were measured using precision Abbes refractometer based on AOAC official method and ISI having a measuring range of refractive index of 1.300-1.700 with the accuracy within \pm 0.0002 . (Ghani et al., 2018) ${ }^{[13]}$. The refractive index was calculated by sandwiching 1 or 2 drops of oil sample between illuminating and refracting prisms of Abbes refractometer by means of syringe. The sample was illuminated with monochromatic light from sodium vapor lamp and it was allowed to stand for $5 \mathrm{~min}$ before taking the reading displayed on the screen.

\subsubsection{Saponification value (SV)}

Coconut oil has a relatively high saponification value due to it high concentration of short and medium chain triglycerides. The saponification value (SV) of the oil samples were determined using the International Union of Pure and Applied Chemistry (IUPAC) method (Rigaudy \& Klesney, 1992) and AOAC official method 920.160. Approximately 2.0g of sample was weighed into a clean dried Erlenmeyer flask and $25 \mathrm{ml}$ of $0.5 \mathrm{~N}$ ethanolic $\mathrm{KOH}$ was added and the mixture was boiled in a reflux condenser for $60 \mathrm{~min}$. The mixture was then cooled to a room temperature and $1 \%$ phenolphthalein solution as an indicator was added to the cooled mixture and subsequently titrated against $0.5 \mathrm{~N} \mathrm{HCl}$ until the color of the mixture changes from pink to colorless. The volume of $\mathrm{HCl}$ was recorded and represented as S. Similarly, the same was repeated for the blank, and the volume of $\mathrm{HCl}$ was noted as $\mathrm{B}$. The saponification value was calculated using.

$$
S V=\frac{(B-S) m l \text { of } \mathrm{HCl} \times 28.05}{\text { weight of sample }(\mathrm{g})}
$$

\subsubsection{Iodine value (IV)}

Iodine value (IV) for the oil samples were determined by using Wijs method (AOCS, 2004). Approximately 4.0g of sample was mixed with $20 \mathrm{ml}$ cyclohexane to dissolve the fat content; $25 \mathrm{ml}$ of Wijs solution was then added. The flask was closed, and the solution was shaken for $30 \mathrm{~min}$ continuously. Simultaneously, $20 \mathrm{ml}$ aqueous KI solution (15\% v/v) and 100 $\mathrm{ml}$ of water were added to the mixture. It was then titrated with $0.1 \mathrm{~N} \mathrm{Na} \mathrm{Na}_{2} \mathrm{O}_{3}$ until the disappearance of yellow color. Then a few drops of starch solution, turning the solution to blue, were added and the titration continued until the blue color vanished. The volume of $\mathrm{Na}_{2} \mathrm{~S}_{2} \mathrm{O}_{3}$ consumed was recorded and represented as $\mathrm{S}$. For the analysis, the same was repeated with blank sample and volume of $\mathrm{Na}_{2} \mathrm{~S}_{2} \mathrm{O}_{3}$ consumed was recorded as $\mathrm{B}$. The IV was calculated using:

$$
\mathrm{IV}=\frac{(\mathrm{B}-\mathrm{S}) \times \mathrm{N} \text { of sodium thiosulphate } \times 12.69}{\text { weight of sample }(\mathrm{g})}
$$

\subsubsection{Acid value (AV)}

An important index of physicochemical property of oil which indicates the quality, age, edibility and suitability of oil for its uses. The acid value (AV) for oil samples were determined by the International Union of Pure and Applied Chemistry (IUPAC) 2.201(1979)/ISO 660:1996). Diethyl ether and ethanol of equal volume $(25 \mathrm{ml})$ were mixed together and $1 \mathrm{ml}$ 
of $1 \%$ phenolphthalein indicator solution was added. The mixture was then neutralized with $0.1 \mathrm{M}$ potassium hydroxide solution and the oil sample (between $1-10 \mathrm{~g}$ ) was dissolved in the neutralized solvent mixture. The sample mixture was then titrated against $0.1 \mathrm{M}$ potassium hydroxide solution with constant shaking until appearance of pink color that persists for about 15 seconds is obtained. The acid value was calculated by:

$$
\mathrm{AV}=\frac{\text { titre value }(\mathrm{ml}) \times 5.61}{\text { weight of sample(g) }}
$$

\subsubsection{Unsaponifiable matter}

The Unsaponifiable matter was determined based on the (Commission, 1999) [6] AOAC, official method 933.08. It uses the neutralized liquid after the titration for the determination of saponification value. The neutralized liquid was transferred quantitatively into a separating funnel using $50 \mathrm{ml}$ of water for washing the flask. It was repeated for 3 times while still warm with $50 \mathrm{ml}$ diethyl ether, all the ether extracts combined into another separating funnel and washed vigorously with $20 \mathrm{ml}$ portions of water and the water was discarded. Following that it was also washed with $20 \mathrm{ml}$ portions of aqueous $0.5 \mathrm{M}$ potassium hydroxide. The extract was transferred into the beaker and kept in boiling water bath for evaporation, 2-3 $\mathrm{cm}^{3}$ acetone was added and heated on water bath. It was further dried to constant weight and then dissolved in $2 \mathrm{ml}$ of diethyl ether. $10 \mathrm{ml}$ of neutralized ethanol was added and titrated with $0.1 \mathrm{M}$ alcoholic potassium hydroxide. The unsaponifiable matter was obtained from the equation:

$$
\text { Unsaponifiable matter }=\frac{\mathrm{M}-0.028 \mathrm{v} \times 1000}{\mathrm{~W}}
$$

Where

$\mathrm{V}=$ volume of potassium hydroxide used

$\mathrm{M}=$ Mass of oil used for saponification value

$\mathrm{W}=$ Mass of unsaponifiable matter

\subsubsection{Polenske value (PV)}

Most of the oils/fats didn't require this test to be performed whereas coconut oil and palm kernel oil contains appreciable quantities of caprylic, capric and lauric acid glycerides and therefore requires this test. The polenske value is historically being determined based on the AOAC 925.41. About $5 \mathrm{~g}$ of oil/fat was weighed and a mixture of $20 \mathrm{~g}$ glycerol and $2 \mathrm{ml}$ of $50 \%$ of $\mathrm{NaOH}$ (Sodium hydroxide) was added. The whole mixture is heated in a Bunsen burner with constant stirring till saponification is initiated (liquid becomes clear) and if liquid is dark it indicates excess heating where the procedure has to be repeated. Then the mixture was cooled to permit the addition of water and distillation is performed. Then the alcoholic solution of insoluble volatile acids was collected after distillation and $0.25 \mathrm{ml}$ of phenolphthalein indicator was added. Finally, it was then titrated against $0.1 \mathrm{~N} \mathrm{NaOH}$ until the disappearance of pink color and the same was performed for blank.

$$
\mathrm{PV}=10 \times \mathrm{V} \times \mathrm{N}
$$

Where

$\mathrm{V}=$ Volume of $\mathrm{NaOH}$ required for titration (in $\mathrm{ml}$ )

$\mathrm{N}=$ Normality of $\mathrm{NaOH}$

\subsubsection{Free fatty acid (FFA)}

The free fatty acid in the oil sample was measured based on the standard Association of Official Agricultural Chemists
(AOAC) method. Approximately 7.0g of different oil samples were mixed with $2 \mathrm{ml}$ of phenolphthalein solution and a few drops of $0.1 \mathrm{M} \mathrm{NaOH}$. Next $50 \mathrm{ml}$ of ethanol was mixed and constantly shaken until a permanent faint pink color was obtained, which was then titrated against $0.25 \mathrm{~N} \mathrm{NaOH}$. The volume of $\mathrm{NaOH}$ spent was recorded as $\mathrm{S}$ and the same was repeated for the blank and the volume was recorded as $\mathrm{B}$. the percentage of free fatty acid was calculated by the formula:

$$
\% \mathrm{FFA}=\frac{(\mathrm{B}-\mathrm{S}) \mathrm{ml} \text { of } \mathrm{NaOH} \times \mathrm{N} \times 56}{1.99 \times \text { weight of sample(g) }}
$$

Where

$\mathrm{N}$-normality of $\mathrm{NaOH}$.

\subsection{Statistical analysis}

The physicochemical properties of oil samples were performed in the set of 5 trials $(n=5)$ for repeatability and reliability. The result is presented as the average value of the data obtained. The mean, standard deviation and standard errors were analyzed using Toolkit in Ms-Excel with the significance level of 95 percent and the quality characteristics were compared.

\section{Result and discussion}

The physicochemical properties of virgin coconut oil (VCO) were compared with the Refined, Bleached, Deodorized (RBD) coconut oil and cold pressed oil (Chekku oil) and represented in the Table. 1 (Asian Pacific Coconut Community, 2009) ${ }^{[3]}$.

\subsection{Moisture content}

The moisture content of oil samples was found to be in the range of $0.10 \%-0.80 \%(\mathrm{w} / \mathrm{w})$, which is within the value recommended by APCC $(<0.5 \% \mathrm{w} / \mathrm{w})$ except the cold pressed oil. This indicates that the VCO were able to produce with low moisture content $0.1 \%$. On the other hand, RBD oil and CPO contain slightly higher moisture content than VCO which may be due to the keeping quality of oil and initiation of oxidation. Lower moisture content of VCO (Choe \& Min, 2006) indicates the increase in shelf life and prevents oxidation and rancidity process.

Table 1: Physicochemical properties of coconut oil samples (RBD, $\mathrm{CPO}$ and $\mathrm{VCO}$ )

\begin{tabular}{|c|c|c|c|c|}
\hline \multirow{2}{*}{ Parameters } & \multicolumn{2}{|c|}{ Coconut oil samples } & \multirow{2}{*}{$\begin{array}{c}\text { APCC } \\
\text { standard }\end{array}$} \\
\cline { 2 - 4 } & RBD & CPO & VCO & Max 0.5 \\
\hline $\mathrm{MC} \%$ & $0.13 \pm 0.005$ & $0.7 \pm 0.044$ & $0.11 \pm 0.008$ & \\
\hline $\mathrm{RI}$ at $40^{\circ} \mathrm{C}$ & 1.4485 & 1.4484 & 1.4487 & $\begin{array}{c}1.4480- \\
1.4492\end{array}$ \\
\hline $\mathrm{SV}(\mathrm{mg} \mathrm{KOH} / \mathrm{g})$ & $252 \pm 0.75$ & $257 \pm 0.63$ & $259 \pm 0.63$ & Min 250 \\
\hline $\mathrm{IV}\left(\mathrm{gI}_{2} / 100 \mathrm{~g}\right)$ & $9.2 \pm 0.074$ & $8.2 \pm 0.04$ & $7.0 \pm 0.06$ & $4.0-11.0$ \\
\hline $\mathrm{AV}(\mathrm{mg} \mathrm{KOH} / \mathrm{g})$ & $0.5 \pm 0.05$ & $0.9 \pm 0.006$ & $2.7 \pm 0.04$ & Max 4.0 \\
\hline $\begin{array}{c}\mathrm{Unsaponifiable} \\
\text { matter \% }\end{array}$ & $0.16 \pm 0.007$ & $0.1 \pm 0.049$ & $0.12 \pm 0.006$ & $<0.5$ \\
\hline $\mathrm{PV} \mathrm{(meqO} / \mathrm{kg})$ & $14.0 \pm 0.10$ & $14.5 \pm 0.05$ & $14.6 \pm 0.06$ & Min 13.0 \\
\hline FFA \% & $0.25 \pm 0.01$ & $0.42 \pm 0.006$ & $1.3 \pm 0.05$ & Max 2.0 \\
\hline
\end{tabular}

RBD-Refined, Bleached and Deodorized coconut oil, CPO-Cold Pressed Oil (Chekku oil), VCO-Virgin coconut oil.

\subsection{Refractive index}

The RI values of the VCO was 1.4487 and that of RBD oil and CPO was 1.4485 and 1.4484 respectively. Results indicate that the refractive index of VCO was higher when compared with RBD and CPO. The values are within the specifications suggested by APCC set proposed. Most 
possibly, the disparity is due to the high FFA and impurity of VCO sample (F. Dayrit et al., 2007) ${ }^{[10]}$. Therefore, certain compositions of FFA results in higher RI of VCO compared with RBD and CPO. Hence, this parameter can be considered for the adulteration detection of $\mathrm{VCO}$ with other vegetable oils.

\subsection{Saponification value}

The SV of VCO was about $259 \mathrm{mg} \mathrm{KOH} / \mathrm{g}$ fats whereas the codex range was between $248-265 \mathrm{mg} \mathrm{KOH} / \mathrm{g}$ fats (Codex, 2001). Comparatively VCO has the highest SV. The SV is related to the mean molecular mass of fats and oils and inversely proportional to the chain length of the fatty acids of fats and oils (Gopala Krishna et al., 2010) ${ }^{[14]}$. Hence, the VCO contains higher content of short chain fatty acids in contrast to RBD and CPO oil.

\subsection{Iodine value}

The samples were found to have IV in the acceptable range compared to the APCC standard (4.0 to 11.0). The lowest IV was noted for the VCO (7.0) whereas the CPO and RBD oil has the IV of 8.2 and 9.2 respectively. Hence, IV indicates the weight percentage of coconut oil related to unsaturated fatty acids that can absorb halogens such as iodine ( $\mathrm{R}$ et al., 2019) [21]. It was analysed that the VCO has less content of unsaturated fatty acids to bind such halogens but the RBD and CPO had higher IV which was due to the presence of high amount of unsaturated fatty acids. Because of the presence of low amount of unsaturated fatty acids safety limit of consuming VCO should be studied and adulteration detection can be made wise with the iodine value.

\subsection{Acid value}

The AV of CPO and RBD oil was $0.9 \mathrm{mg} \mathrm{KOH} / \mathrm{g}$ and $0.5 \mathrm{mg}$ $\mathrm{KOH} / \mathrm{g}$ respectively, much lower than the $\mathrm{VCO}(2.7 \mathrm{mg}$ $\mathrm{KOH} / \mathrm{g}$ ) and moreover all the samples were within the APCC limit. It can be understood that the behaviour of either lipase activity or light and heat exposure was relatively higher in VCO rather than other samples (Akubugwo et al., 2008; Warra et al., 2011) ${ }^{[2,28]}$. The lipase activity and hydrolytic action or oxidation was used to correlate the $\%$ FFA in fat or oil.

\subsection{Unsaponifiable matter}

VCO and CPO, which have the highest saponification value of 259 and $257 \mathrm{mg} \mathrm{KOH} / \mathrm{g}$, also have the lowest unsaponifiable matter of 0.12 per cent and 0.1 per cent, respectively, which confirms that their properties will be ideally suited for soap production compared to 0.16 per cent in RBD oil and would be better suited for use in cosmetics. This would also refer to those substances that are not saponifiable by alkali hydroxides but soluble in regular fat solvents (Afolayan et al., 2014) ${ }^{[1]}$ and to products of saponification that are soluble in such solvents.

\subsection{Polenske value}

In comparison VCO has slightly high PV of $14.6 \mathrm{~m}-\mathrm{eqO}_{2} / \mathrm{kg}$ than CPO and RBD oil having $14.5 \mathrm{~m}-\mathrm{eqO}_{2} / \mathrm{kg}$ and $14.0 \mathrm{~m}-$ $\mathrm{eqO}_{2} / \mathrm{kg}$ respectively. Results reveal that the VCO has higher quantities of caprylic, capric and lauric acids. These glycerides form the composition of free fatty acids. Therefore, higher PV would indicate the presence of high \% FFA. These fatty acids are steam volatile but insoluble in water and gives high polenske number (Nwinuka N.M et al., 2009). It can be observed that PV is directly related to the free fatty acids present in the sample.

\subsection{Free fatty acids}

The \% FFA of all the samples were in the range of $0.25 \%$ $1.3 \%$ which was acceptable and within the recommended limit by APCC. However, RBD oil has the lowest \% FFA when compared to CPO and VCO. FFA are produced by the hydrolysis of oils and fats and are susceptible to oxidation (Kumar \& Krishna, 2015; Marina et al., 2009) ${ }^{[29,17]}$. In RBD oil while processing with chemical treatments it may be reduced and regulated without supressing the quality. FFA can be used as an indicator of taste and aroma of oil. The trend followed to interrupt \% FFA from refractive index, acid value and polenske value in oil samples can be used vice versa.

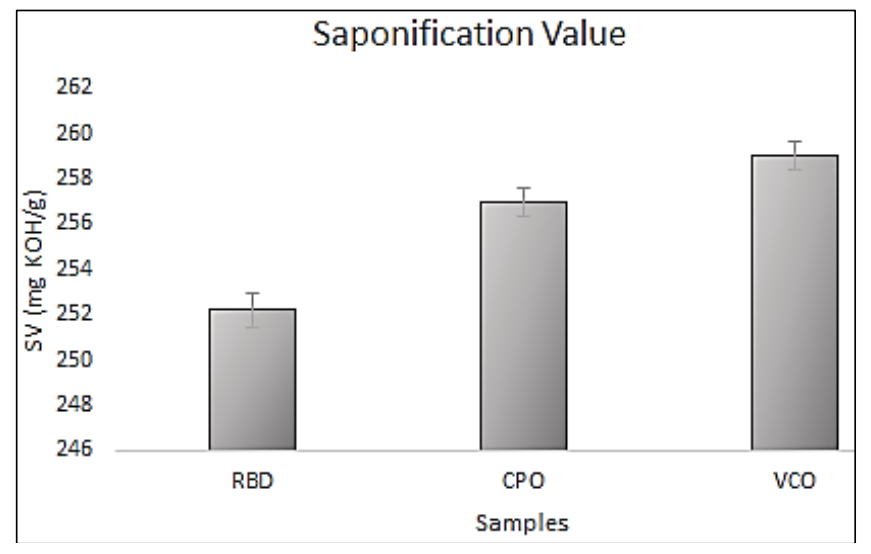

(A)

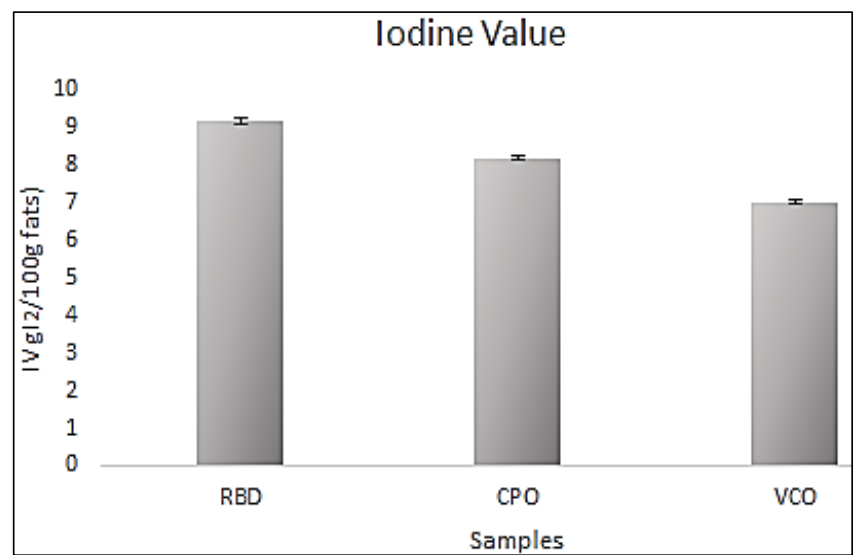

(B)

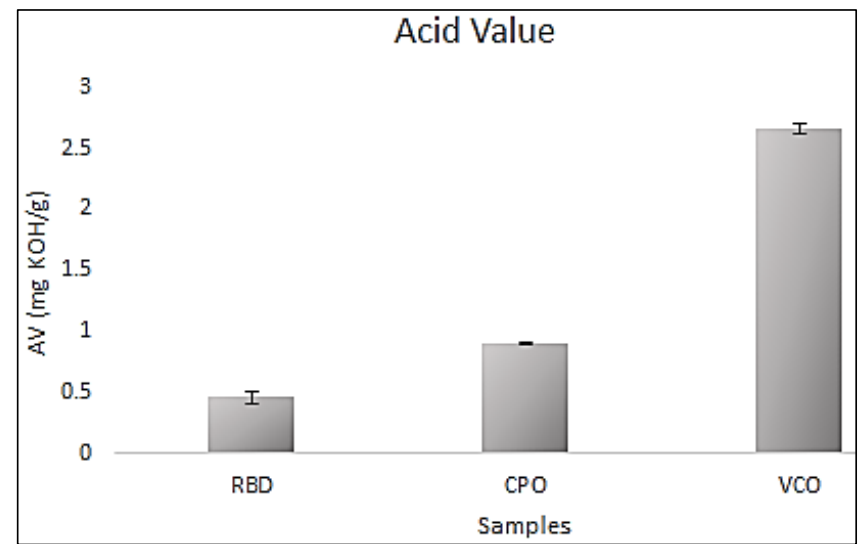

(C) 


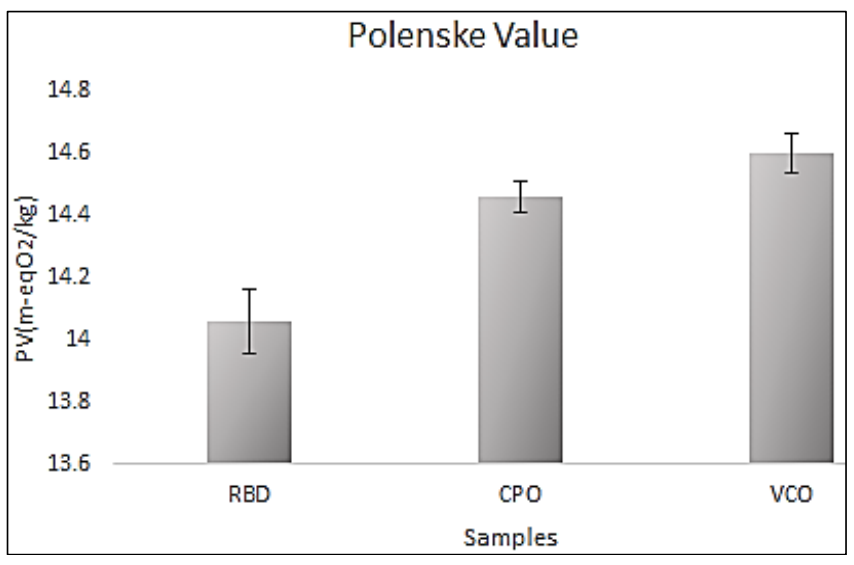

(D)

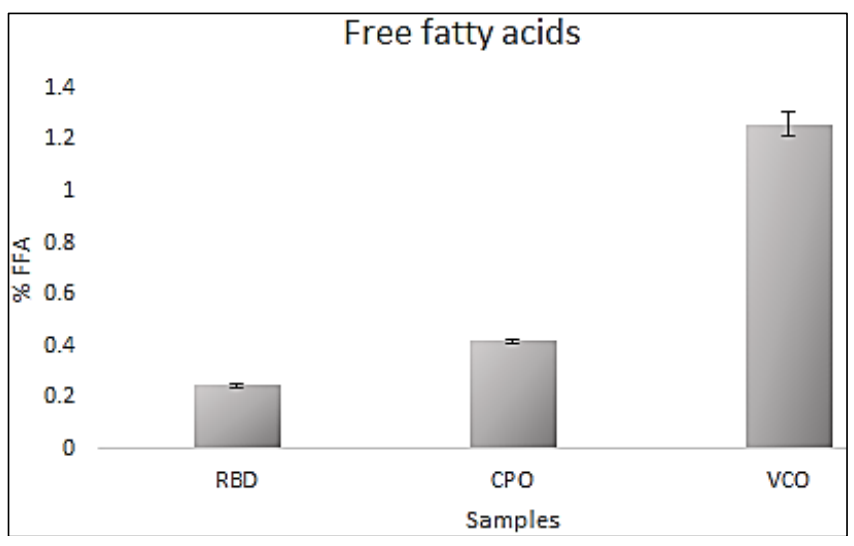

(E)

Fig 1: Comparative study on physicochemical properties of VCO with other coconut oil samples (A) Saponification Value, (B) Iodine Value, (C) Acid Value, (D) Polenske Value, (E) Free fatty acids

\section{Conclusions}

This research findings reveals that most of the physicochemical properties tested are within the acceptable range referred by APCC $2009^{[3]}$ (Standard, 2009) ${ }^{[26]}$. The Iodine value of the VCO was $7.0 \mathrm{gI}_{2} / 100 \mathrm{~g}$, which was lower compared to other samples of coconut oil, indicating that the VCO has more oxidation stability and the lower moisture content of VCO could enhance the shelf life of oil. The FFA of VCO was $1.3 \%$ which was slightly higher, would mean that consumption for cooking purpose was minimal. VCO showed good results against the RBD coconut oil and CPO which can be used in the cooking and other edible purposes ensuring quality and safety. Therefore, the parameters including SV, AV, IV and \% FFA can be used for the adulteration detection of VCO to have significant results.

\section{References}

1. Afolayan M, Fausat A, Idowu D. Extraction and physicochemical analysis of some selected seed oils. International Journal of Advanced Chemistry 2014;2(2):70-73. https://doi.org/10.14419/ijac.v2i2.2203

2. Akubugwo IE, Chinyere GC, Ugbogu AE. Comparative studies on oils from some common plant seeds in Nigeria. Pakistan Journal of Nutrition 2008;7(4):570-573. https://doi.org/10.3923/pjn.2008.570.573

3. APCC. Virgin Coconut Oil Asian and Pacific Coconut Community 2009.

4. Asian Pacific Coconut Community. APCC Quality Standard Virgin Coconut Oil. Asian and Pacific Coconut Community

2009. http://www.apccsec.org/apccsec/media.php?page=apccsta ndar\&act=view\&id=3

5. Assunção ML, Ferreira HS, Dos Santos AF, Cabral CR, Florêncio TMMT. Effects of dietary coconut oil on the biochemical and anthropometric profiles of women presenting abdominal obesity. Lipids 2009;44(7):593-601. https://doi.org/10.1007/s11745-009-3306-6

6. Commission CA. Recommended methods of analysis and sampling 1999, 1-48.

7. Da Silva Lima R, Block JM. Coconut oil: What do we really know about it so far? Food Quality and Safety 2019;3(2):61-72. https://doi.org/10.1093/fqsafe/fyz004

8. Dayrit F, Buenafe OE, Chainani E, De Vera IM, Dimzon IK, Gonzales E et al. Standards for essential composition and quality factors of commercial virgin coconut oil and its differentiation from RBD coconut oil and copra oil. Philippine Journal of Science 2007.

9. Dayrit FM. The Properties of Lauric Acid and Their Significance in Coconut Oil. Journal of the American Oil Chemists' Society 2015;92(1):1-15. https://doi.org/10.1007/s11746-014-2562-7

10. Dayrit FM, Buenafe OEM, Chainani ET, Vera IMS, De Dimzon IKD, Gonzales EG et al. Essential quality parameters of commercial Virgin Coconut Oil. Cord (APCC) 2007;23(1).

11. Dia VP, Garcia VV, Mabesa RC, Tecson-Mendoza EM. Comparative physicochemical characteristics of virgin coconut oil produced by different methods. Philippine Agricultural Scientist 2005;88(4):462-475.

12. German JB, Dillard CJ. Saturated fats: What dietary intake? American Journal of Clinical Nutrition 2004;80(3):550-559. https://doi.org/10.1093/ajcn/80.3.550

13. Ghani NAA, Channip AA, Chok Hwee Hwa P, Ja'afar F, Yasin HM, Usman A. Physicochemical properties, antioxidant capacities, and metal contents of virgin coconut oil produced by wet and dry processes. Food Science and Nutrition 2018;6(5):1298-1306. https://doi.org/10.1002/fsn3.671

14. Gopala KA, Gaurav R, Bhatnagar AS, Prasanth KPK, Preet C. Coconut Oil: Chemistry, Production and Its Applications-A Review. Indian Coconut Journal 2010;53(3):15-27.

15. Satheeshan KN, Seema BR, Meera Manjusha AV. Development of virgin coconut oil based body lotion. Pharma Innovation. 2020;9(5):96-101.

16. List GR. Oilseed Composition and Modification for Health and Nutrition. In Functional Dietary Lipids: Food Formulation, Consumer Issues and Innovation for Health. Elsevier Ltd., 2016. https://doi.org/10.1016/B978-178242-247-1.00002-8

17. Marina AM, Che Ma YB, Nazimah SAH, Amin I. Chemical properties of virgin coconut oil. JAOCS, Journal of the American Oil Chemists' Society 2009;86(4):301307. https://doi.org/10.1007/s11746-009-1351-1

18. Nevin KG, Rajamohan T. Beneficial effects of virgin coconut oil on lipid parameters and in vitro LDL oxidation. Clinical Biochemistry 2004;37(9):830-835. https://doi.org/10.1016/j.clinbiochem.2004.04.010

19. Nevin KG, Rajamohan T. Food Chemistry Virgin coconut oil supplemented diet increases the antioxidant status in rats 2006;99:260-266. https://doi.org/10.1016/j.foodchem.2005.06.056

20. Perera DN, Hewavitharana GG, Navaratne SB. Determination of Physicochemical and Functional Properties of Coconut Oil by Incorporating Bioactive 
Compounds in Selected Spices. Journal of Lipids 2020, 111. https://doi.org/10.1155/2020/8853940

21. R DN, Natalia A, Lukmanto F, Ani I, Tarigan IL. Analysis quality characteristics of virgin coconut oil (VCO): comparisons with cooking coconut oil (CCO). Medical Laboratory Analysis and Sciences Journal 2019;1(1):3036. https://doi.org/10.35584/melysa.v1i1.20

22. Raghavendra SN, Raghavarao KSMS. Effect of different treatments for the destabilization of coconut milk emulsion. Journal of Food Engineering 2010;97(3):341347. https://doi.org/10.1016/j.jfoodeng.2009.10.027

23. Savva SC, Kafatos A. Vegetable Oils: Dietary Importance. In Encyclopedia of Food and Health (1st ed.). Elsevier Ltd. 2015. https://doi.org/10.1016/B978-0-12-3849472.00709-1

24. Schönfeld P, Wojtczak L. Short and medium-chain fatty acids in energy metabolism: The cellular perspective. In Journal of Lipid Research 2016;57(6). https://doi.org/10.1194/jlr.R067629

25. Srivastava Y, Semwal AD, Sharma GK. Virgin Coconut Oil as Functional Oil. In Therapeutic, Probiotic, and Unconventional Foods. Elsevier Inc. 2018. https://doi.org/10.1016/B978-0-12-814625-5.00015-7

26. Standard AQ. Apcc Quality Standard 2009.

27. Vidya TA, Seeja TP. Virgin coconut oil. Indian Coconut Journal 2016, 23-29.

28. Warra A, Wawata I, Gunu S, Aujara KM. Extraction and Physicochemical Analysis of some selected Northern Nigerian Industrial oils. Archives of Applied Science Research 2011;3(4):536-541. https://www.researchgate.net/profile/Aliyu_Ahmad_Warr a/publication/215651542_Extraction_and_Physicochemic al_Analysis_of_some_selected_Northern_Nigerian_Indust rial_oils/links/53ec75370cf202d087d0257d.pdf

29. Kumar PKP, Krishna AGG. Physicochemical characteristics of commercial coconut oils produced in India. Grasas y Aceites 2015;66(1):1-12. https://doi.org/10.3989/gya.0228141 